\title{
INDUCTION OF MICROSPORE EMBRYOGENESIS IN CULTURED ANTHERS OF HORDEUM VULGARE. THE EFFECTS OF AMMONIUM NITRATE, GLUTAMINE AND ASPARAGINE AS NITROGEN SOURCES
}

by

\author{
FINN LOK OLSEN \\ Department of Physiology, Carlsberg Laboratory, \\ Gl. Carlsberg Vej 10, DK-2500 Copenhagen Valby
}

Keywords: Premature germination, embryoids, agarose, Ficoll

\begin{abstract}
Improvement of the yield of green plants was obtained by decreasing the concentration of ammonium nitrate in the culture medium and using glutamine as a nontoxic nitrogen source. Embryoids developed directly from the microspores on such media, and frequently green plants were obtained by germination of the embryoids on the induction medium, whereas formation of calli was greatly reduced.

Ficoll was tested as a carrier agent in liquid barley anther culture. It gave a higher total yield of embryoids resulting from an increased number of responding anthers and an increased number of developed structures. When anthers were floated on a Ficoll medium surface the microspores developed inside the anther. After several mitotic divisions the anther wall burst and the proembryoids were expelled onto the surface of the medium. Here their development continued by germination. The substitution of ammonium nitrate by glutamine or asparagine in the liquid medium containing Ficoll was found to be beneficial for culture development.

This report is based on the regeneration of 6,827 green plants, with an optimal average ratio of green to albino plants of 1.8. A frequency of 4.6 green plants per plated anther was obtained.
\end{abstract}

\section{INTRODUCTION}

The importance of induction of haploids and their chromosome doubling, as an alternative to the numerous cycles of inbreeding or backcrossing needed to obtain pure lines in conventional breeding programs, has been reiterated in a large number of reports and reviews during the last two decades (20).

In barley several methods have been used to induce haploidy including the use of the Hap gene (9), ovary (27) and anther (3) culture, and interspecific hybridization between Hordeum vulgare and $\mathrm{H}$. bulbosum followed by spontaneous elimination of the latter genome (14). Of these only the bulbosum method is well established in commercial breeding programs (21).

Despite a potentially higher yield of haploid plants from microspores through anther culture, this technique has so far not been used routinely in commercial breeding programs due to a low frequency of regenerated plants, a high proportion of albinos, and a considerable variation in the ploidy level (13). One of the few cases where this method has been successfully used in practical plant breeding is in the transfer of barley yellow mosaic virus resistance to commercial varieties as reported by FOROUGHI-WEHR et al. (8).

Abbreviations: BAP $=6$-benzylaminopurine; $\mathrm{G} / \mathrm{A}$ ratio $=$ Green plant/Albino plant ratio; $\mathrm{HMT}=$ high melting temperature; MS medium = MURASHIGE and SKOOG (18); LMT = low melting temperature; RH = relative humidity. 
Numerous modifications of the growth conditions for the donor plants as well as of the cultivation conditions and the media for the growth of excised anthers have been tested, but in most cases there have been only minor improvements in the number of green plants per anther. The successful cultivation of anthers with these systems is based on disintegration of the microspores and subsequent formation of calli, from which green plants have been obtained at low frequencies, typically 0.02 green plants per plated anther in the cv. Igri (8).

Recently, an increased frequency of green plants was reported by LYNE et al. (17) when agarose replaced agar as the solidifier of the medium, in agreement with the earlier observations by SHILLITO et al. (22) who showed that the growth of protoplasts from several plant species was stimulated if agarose was used instead of agar.

Further improvement in the yield was obtained if cultivation of barley anthers was performed in an atmosphere of high humidity (17). This, in combination with the presence of a larger free space above the culture and a high gas exchange rate, promoted the growth of microspores from cultured anthers (17), confirming earlier observations on cultivated tobacco anthers $(5,6)$.

Finally, it was observed by HUNTER (12) that the orientation of the barley anther on the agarose medium had a pronounced effect on the yield. When only one loculus of the anther was in contact with the medium a significantly higher response was obtained compared to an orientation where both loculi touched the medium. A similar effect of the orientation of the anther was reported for Datura anthers (23), except that in this case the maximum frequency of green plants was obtained when both loculi were in contact with the medium.

The combination of the correct/optimal physical orientation of the anther on the medium, high humidity, increased gas exchange in the culture vessel and the use of highly purified agarose frequently induces the development of embryoids from microspores in the cultivated anthers rather than formation of calli, the resultant embryoids being far more easily regenerated into green plants than the amorphous calli obtained with less optimal cultivation and growth conditions.

It has recently been shown by KAO and HORN (15) that an increase of the frequency of responding anthers could be obtained in liquid culture medium containing Ficoll 400 as a buoyancy increasing component. On similar media DATTA (4) reported that direct pollen embryogenesis was possible from cold pretreated whole spike cultures.

The present study was undertaken in order to exploit the possibilities of optimizing the conditions for production of haploid barley plants through cultivation of excised anthers from winter barley, using the improvement of the cultivation conditions described above.

\section{MATERIALS AND METHODS}

\subsection{Materials}

Seeds of barley (Hordeum vulgare L.) variety Igri (winter type) were kindly provided by Dr. C.P. HunTER, Shell Research Ltd, Sittingbourne, Kent, UK.

\subsection{Methods}

\subsubsection{Donor plants}

Seeds were germinated in a 1:1:2 soil mix, composed of K-soil (Sphagnum), Peat compost and Perlite, in 0.2 liter pots, at $20^{\circ} \mathrm{C}, 85 \% \mathrm{RH}$, and a $24 \mathrm{~h}$ day $\left(40 \mu \mathrm{E} \cdot \mathrm{m}^{-2} \cdot \mathrm{s}^{-1}\right.$ Philips cold white). The light intensity is in all cases measured at the top of the pot or other culture containers.

After 5-6 days, when the plantlets had reached a height of about $5 \mathrm{~cm}$ the pots were transferred to a vernalization room $\left(4{ }^{\circ} \mathrm{C}, 85 \% \mathrm{RH}\right.$ and $10 \mathrm{~h}$ light, $105 \mu \mathrm{E} \cdot \mathrm{m}^{-2} \cdot \mathrm{s}^{-1}$ Philips warm white). The pots were placed on a capillary mat in a pool of water which gave a continuous supply of water.

After eight weeks the plants were potted in 1.5 liter pots, in the same soil mixture as was used for germination and vernalization, and placed in a Conviron E8 growth chamber at $12^{\circ} \mathrm{C}, 70-80 \%$ $\mathrm{RH}$ and $16 \mathrm{~h}$ light $\left(120 \mu \mathrm{E} \cdot \mathrm{m}^{-2} \cdot \mathrm{s}^{-1}\right.$ Sylvania WHO/incandescent bulbs, $75 \% / 25 \%$ on watt basis).

The pots were placed on a capillary mat in trays which allowed draining of excess water. 
Table I. Nutrient supply for donor plants. Milliliters of liquid fertilizer (1:2 mixture of Chempack Numbers 1 and 2, (Chempack, Hoddesdon, Herts, UK) final concentration $6.75 \mathrm{~g} \mathrm{l}^{-1}$ (25:11:11 N:P:K) applied per $1.5 \mathrm{l}$ pot).

\begin{tabular}{|c|c|c|c|c|c|c|c|c|c|}
\hline Week & & 0 & 1 & 2 & 3 & 4 & 5 & 6 & 7 \\
\hline \multirow{4}{*}{ Day } & 1 & - & 5 & 5 & 10 & 10 & 10 & 10 & 10 \\
\hline & 3 & - & - & - & 10 & 10 & 10 & 10 & 10 \\
\hline & 5 & - & - & 5 & 5 & 10 & 10 & 10 & 10 \\
\hline & 7 & - & - & - & - & 5 & 5 & 5 & 5 \\
\hline
\end{tabular}

The duration of the growth period was approximately 7 weeks. Liquid fertilizer was applied 4 times a week according to the schedule (Table I) kindly provided by Dr. HUNTER.

\subsubsection{Tissue culture}

The spikes were harvested when the pollen was in the mid uninucleate stage. Spikes at the desired developmental stage were preselected on

Table II. Media for anther culture in Hordeum. Modified MS medium after ForoughI-WEHR et al. (7), KAO and HORN (16) and HUNTER (12).

\begin{tabular}{|c|c|c|c|}
\hline & I & II & III \\
\hline Macroelements & $\mathbf{m g ~ l ^ { - 1 }}$ & $\mathrm{mg} \mathrm{l}^{-1}$ & $\mathrm{mg} \mathrm{l}^{-1}$ \\
\hline $\mathrm{NH}_{4} \mathrm{NO}_{3}$ & 165 & 165 & 165 \\
\hline $\mathrm{KNO}_{3}$ & 1900 & 1900 & 1900 \\
\hline $\mathrm{CaCl}_{2}, 2 \mathrm{H}_{2} \mathrm{O}$ & 440 & 440 & 440 \\
\hline $\mathrm{MgSO}_{4}, 7 \mathrm{H}_{2} \mathrm{O}$ & 370 & 370 & 370 \\
\hline $\mathrm{KH}_{2} \mathrm{PO}_{4}$ & 170 & 170 & 170 \\
\hline $\mathrm{FeNa}$, EDTA & 40 & 40 & 40 \\
\hline \multicolumn{4}{|l|}{ Microelements } \\
\hline $\mathrm{H}_{3} \mathrm{BO}_{3}$ & 6.2 & 6.2 & 6.2 \\
\hline $\mathrm{MnSO}_{4}, 4 \mathrm{H}_{2} \mathrm{O}$ & 22.3 & 22.3 & 22.3 \\
\hline $\mathrm{ZnSO}_{4}, 4 \mathrm{H}_{2} \mathrm{O}$ & 8.6 & 8.6 & 8.6 \\
\hline KI & 0.83 & 0.83 & 0.83 \\
\hline $\mathrm{Na}_{2} \mathrm{MoO}_{4}, 2 \mathrm{H}_{2} \mathrm{O}$ & 0.25 & 0.25 & 0.25 \\
\hline $\mathrm{CuSO}_{4}, 5 \mathrm{H}_{2} \mathrm{O}$ & 0.025 & 0.025 & 0.025 \\
\hline \multicolumn{4}{|l|}{ Organic elements } \\
\hline BAP & 1 & 0.4 & - \\
\hline Glutamine & 750 & 750 & 750 \\
\hline Myo-inositol & 100 & 100 & 100 \\
\hline Thiamine $\mathrm{HCl}$ & 0.4 & 0.4 & 0.4 \\
\hline Sucrose & 60.000 & 35,000 & 20,000 \\
\hline $\begin{array}{l}\text { Ficoll } 400 \\
\text { or }\end{array}$ & 200,000 & - & - \\
\hline SeaPlaque agarose (LMT) & 8,000 & - & - \\
\hline Litex HSB agarose (HMT) & - & 6,000 & 6,000 \\
\hline \multicolumn{4}{|l|}{ Preparation } \\
\hline \multicolumn{4}{|c|}{$\begin{array}{l}\text { Macro- and microelements and organic elements are made up two times concentrated, the } \mathrm{pH} \text { adjusted to } 5.6 \\
\text { with } 1 \mathrm{M}-\mathrm{NaOH} \text { and the solution sterile filtered }(0,22 \mu \mathrm{m} \text { pore size) before the addition of an equal volume of } \\
\text { two times concentrated, autoclaved agarose or Ficoll solution. }\end{array}$} \\
\hline
\end{tabular}


the basis of the interligule length between the flag leaf and the second leaf, and on the thickness of the tiller.

Before the spikes were removed from the ensheathing leaves, the tillers were surface sterilized with an aerosol of $96 \%$ ethanol. Anthers from a floret in the middle of the spike were stained with a $2: 1$ mixture of $4 \%$ acetocarmine: $1 \%$ potassium iodine and examined in the light microscope to confirm the initial staging.

Spikes containing anthers in the mid uninucleate stage were cold pretreated at $4{ }^{\circ} \mathrm{C}$ for 28 days in two-compartment Petri dishes (Sterilin 501) as described by HuANG and SUNDERLAND (11).

Anthers surviving the cold pretreatment were removed under a dissecting microscope using fine tipped forceps (Dumoxel No. 5), taking care not to rupture the anthers. This was faciliated by bending the lower innermost awn anteriorly, prior to removing the anthers. The anthers were placed directly on solid medium I (Table II) and oriented so that only one loculus was in contact with the medium as described by HUNTER (12). The density of the innoculum was two to three anthers per milliliter of medium.

The media used (Medium I, Table II) are modified MS media (18), as described by ForOUGHI-WEHR et al. (7), solidified with $0.8 \%$ SeaPlaque Agarose (FMC Bioproducts, Maine) for induction of culture on solid medium or containing 20\% Ficoll 400 (Pharmacia) for induction on liquid medium. For regeneration $0.6 \%$ Litex HBS agarose (Litex, Denmark) was used (Media II and III). The media were prepared as described in the legend to Table II. Nutritional elements were from Merck, organic elements from Sigma and Fe-EDTA from Fluka. In addition to the media listed in Table II, culture experiments were performed on media in which the concentration of ammonium nitrate, glutamine and asparagine were changed as described in sections 3.1 and 3.2 .

The culture container, a $50 \mathrm{~mm}$ Petri dish, 18 $\mathrm{mm}$ high (Sterilin 124), was sealed with Nescofilm (Nippon Shoji Kaisha, Osaka, Japan) and placed inside a $140 \mathrm{~mm}$ Petri dish together with an unsealed $50 \mathrm{~mm}$ Petri dish containing water. The large Petri dish was finally sealed with Nescofilm as described by LYNE et al. (17).
The cultures were incubated at $25^{\circ} \mathrm{C}$ in the dark. Calli or embryoids larger than $2 \mathrm{~mm}$ were transferred to medium II, at a density of 16 structures per $10 \mathrm{ml}$ of medium per Petri dish (Sterilin 124), $\left(20 \mathrm{~cm}^{3}\right.$ air above the culture) and were incubated in the dark for 5 days at $25^{\circ} \mathrm{C}$. Thereafter, the cultures were maintained at 23 ${ }^{\circ} \mathrm{C}, 10 \mathrm{~h}$ light, $\left(60 \mu \mathrm{E} \cdot \mathrm{m}^{-2} \cdot \mathrm{s}^{-1}\right.$ Philips cold white $)$ until greening of the coleoptile was observed.

The green plantlets were then transferred to medium III for further development. Each $60 \mathrm{ml}$ containers (Sterilin $125 \mathrm{AP}$ ) holding one green plantlet and $25 \mathrm{ml}$ medium, at $23^{\circ} \mathrm{C}, 10 \mathrm{~h}$ light, $\left(60 \mu \mathrm{E} \cdot \mathrm{m}^{-2} \cdot \mathrm{s}^{-1}\right.$ Philips cold white).

When several shoots and roots had developed, the plants were vernalized while still in the containers for root development $\left(4{ }^{\circ} \mathrm{C}, 10 \mathrm{~h}\right.$ light, $20 \mu \mathrm{E} \cdot \mathrm{m}^{-2} \cdot \mathrm{s}^{-1}$ Philips warm white). After 6 weeks the plants, together with the surrounding solid medium, were potted in $\mathrm{K}$-soil and transferred to a greenhouse.

\section{RESULTS}

\subsection{Agar and agarose as solidifier of the culture media}

Agar is the most commonly used gelling agent in plant tissue culture. It has, however, been shown that in the case of recalcitrant protoplast cultures the use of SeaPlaque agarose as solidifier of the medium, instead of agar, greatly stimulated the formation of colonies (22).

As proposed by SHILliTo et al. (22) this is most likely due to the chemical difference between agar and agarose. Agar consists of neutral agarose and ionic agaropectin, with a large number of attached side groups, whereas highly purified agarose is based on repeated arabinose units (1). Agarose is less toxic to the cultures than agar probably because agarose is devoid of sulphate ester side groups.

This is consistent with the observation made by LYNE et al. (17), that embryogenic development occurred more frequently on medium solidified with SeaPlaque agarose rather than agar, resulting in an increased green plant production. SeaPlaque agarose in combination with vertical orientation of the anther (12) strongly promoted the formation of embryoids, and the formation of amorphous calli was depressed. 
These observations were confirmed by the initial culture experiments, in which agar was used as solidifier of the medium. Subsequent cultures were therefore maintained either on agarose medium (experiments 1 and 2) or on liquid medium, in which the buoyancy was increased by addition of Ficoll 400 (experiments 3 and 4).

\subsubsection{Experiment 1. Comparison between ammonium nitrate and glutamine as nitrogen sources in the induction medium}

It has previously been reported by CLAPHAM (3) that cultures of barley anthers showed an increased response if plated on modified MS medium containing $2 \mathrm{~mm}$-ammonium nitrate instead of $20 \mathrm{~mm}-\mathrm{NH}_{4} \mathrm{NO}_{3}$ as-was originally used in the MS medium (18).

For Nicotiana isolated pollen cultures NITSCH (19) has reported that $5.5 \mathrm{~mm}$ of glutamine in combination with $1 \mathrm{mM}$-serine was beneficial for embryogenic culture development. WERNICKE and KOHLENBACH (24) have confirmed that the embryogenic effect was due to the addition of glutamine in Nicotiana cultures, and in carrot suspension cultures, glutamine was observed to support good growth and embryogenesis (25).

In wheat anther culture HENRY and DE BUYSER (10) have shown that glutamine could replace potato extract, and that the optimal glutamine concentration was $3.4 \mathrm{~mm}$ in liquid medium, whereas concentrations of 6.8 and $13.6 \mathrm{~mm}$-glutamine resulted in a reduction of the number of responding anthers. On the other hand, it was reported by XU and SUNDERLAND (26) that glutamine at 1.1 or $5.5 \mathrm{~mm}$ in combination with myo-inositol at respectively 5.5 or 27.7 $\mathrm{mM}$ in medium solidified by agar was either ineffective or inhibitory for barley pollen callus production.

The present experiment was designed to determine if glutamine was able to stimulate embryogenesis from barley microspores.

An equal number of anthers, taken from either side of the spike, was plated on MS medium containing $20 \mathrm{mM}-\mathrm{NH}_{4} \mathrm{NO}_{3}$, standard in MS medium (18) and on MS medium con-

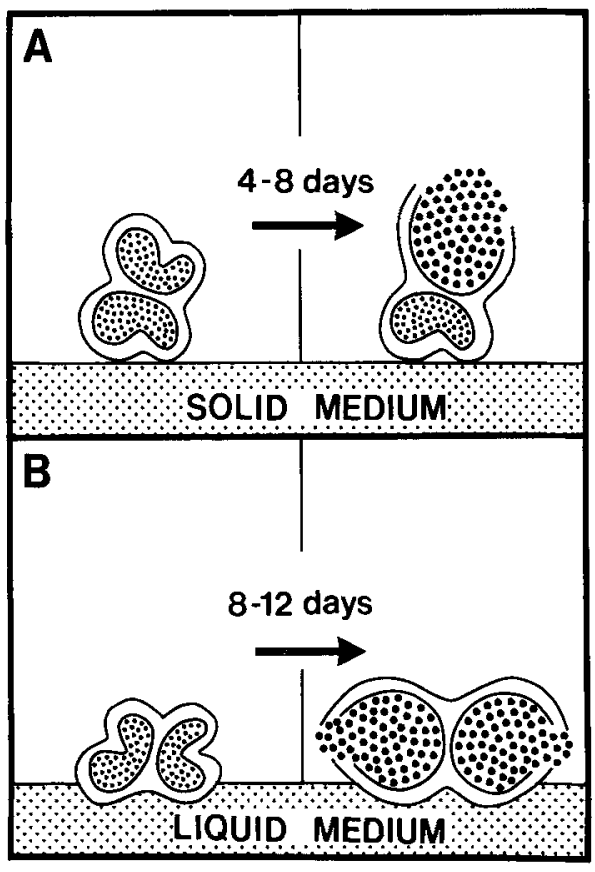

Figure 1. A) Cross section of an anther orientated with one loculus in contact with the solid medium. During the first week of culture the upper loculus opens in response to the increasing volume of the developing microspores. No response is observed from the loculus in contact with the medium.

B) Anther orientated with both loculi in contact with the liquid medium. The developing microspores burst the anther wall after one week of culture, this is observed in both loculi.

taining $2 \mathrm{~mm}-\mathrm{NH}_{4} \mathrm{NO}_{3}$ and $5.1 \mathrm{~mm}$-glutamine, respectively.

The data (Table II) are based on 12 spikes each providing 30 anthers for each of the two media. The plating density was 3 anthers per milliliter medium.

On a medium containing $2 \mathrm{mM}-\mathrm{NH}_{4} \mathrm{NO}_{3}$ and $5.1 \mathrm{~mm}$-glutamine the upper loculus of the oriented anther started to open after 4-8 days, (Figure 1A). The microspores, lying in the cavity between the anther walls, enlarged and synchronously developed into embryogenic structures. The embryogenic development was characterized by the formation of spherical structures with a uniformly granulated surface and a light yellow colour. This was the most prevailing 
Table III. Plant formation from cultured anthers of Hordeum vulgare c.v. Igri on modified MS medium.

\begin{tabular}{|c|c|c|c|c|c|c|c|c|c|}
\hline & \multirow[b]{2}{*}{ Mediumas $^{a}$} & \multirow{2}{*}{$\begin{array}{l}\text { Number } \\
\text { of } \\
\text { plated } \\
\text { anthers }\end{array}$} & \multirow{2}{*}{$\begin{array}{l}\text { Number } \\
\text { of re- } \\
\text { sponding } \\
\text { anthers }^{\text {b) }}\end{array}$} & \multirow{2}{*}{$\begin{array}{l}\text { Percent } \\
\text { respond- } \\
\text { ing } \\
\text { anthers }\end{array}$} & \multicolumn{2}{|c|}{ Green plants } & \multicolumn{2}{|c|}{ Albino plants } & \multirow{2}{*}{$\begin{array}{l}\text { Green/Albino } \\
\text { ratio } \\
\text { (G/A) }\end{array}$} \\
\hline & & & & & total & $\begin{array}{l}\text { per re- } \\
\text { sponding } \\
\text { anther }\end{array}$ & total & $\begin{array}{l}\text { per re- } \\
\text { sponding } \\
\text { anther }\end{array}$ & \\
\hline \multicolumn{10}{|l|}{ agarose } \\
\hline \multirow{2}{*}{ Exp. 1} & $\begin{array}{l}2 \mathrm{~mm}-\mathrm{NH}_{4} \mathrm{NO}_{3} \\
+5.1 \mathrm{mM}-\mathrm{Gln}\end{array}$ & 360 & 107 & 30 & 346 & 3.2 & 233 & 2.2 & 1.5 \\
\hline & $20 \mathrm{mM}-\mathrm{NH}_{4} \mathrm{NO}_{3}$ & 360 & 62 & 17 & 72 & 1.2 & 94 & 1.5 & 0.8 \\
\hline \multirow{3}{*}{ Exp. 2} & $3.4 \mathrm{~mm}-\mathrm{Gln}$ & 200 & 64 & 32 & 218 & 3.4 & 175 & 2.7 & 1.2 \\
\hline & $5.1 \mathrm{~mm}-\mathrm{Gln}$ & 200 & 70 & 35 & 271 & 3.9 & 172 & 2.5 & 1.6 \\
\hline & $6.8 \mathrm{mM}-\mathrm{Gln}$ & 200 & 59 & 30 & 197 & 3.3 & 140 & 2.4 & 1.4 \\
\hline \multicolumn{10}{|l|}{ Ficoll } \\
\hline \multirow{2}{*}{ Exp. 3} & $3.4 \mathrm{~mm}-\mathrm{Gln}$ & 420 & 319 & 76 & 1537 & 4.8 & 867 & 2.7 & 1.8 \\
\hline & $5.1 \mathrm{~mm}-\mathrm{Gln}$ & 420 & 344 & 82 & 1949 & 5.7 & 982 & 2.9 & 2.0 \\
\hline \multirow{2}{*}{ Exp. 4} & $5.1 \mathrm{~mm}-\mathrm{Gln}$ & 450 & 307 & 68 & 1190 & 3.9 & 707 & 2.3 & 1.7 \\
\hline & $5.1 \mathrm{~mm}-\mathrm{Asn}$ & 450 & 291 & 65 & 1047 & 3.6 & 755 & 2.6 & 1.4 \\
\hline
\end{tabular}

a) Medium I, Table II, was employed except for the variables given.

b) Anthers developing calli or embryoids.

type of structure on medium containing glutamine.

Subsequent embryogenic development continued leading to a well formed scutellum and an easily distinguished coleoptile and coleorhiza was observed frequently. As the size of the microspore derived embryoids further increased, the space in the anther cavity became insufficient and the faster developing embryoids fell onto the surface of the medium. When the embryoids reached a size larger than 2-3 mm they were transferred to medium II/Table II and were oriented with the scutellum against the surface of the medium to ensure optimal conditions for germination. Embryoids not removed in time germinated on the induction medium.

Microspores in anthers cultured on the 20 mM- $\mathrm{NH}_{4} \mathrm{NO}_{4}$ medium showed a very different pattern of development in comparison to cultures on $2 \mathrm{mM}-\mathrm{NH}_{4} \mathrm{NO}_{3}$ supplemented with 5.1 mM-glutamine. Fewer anthers responded on the medium with the higher level of $\mathrm{NH}_{4} \mathrm{NO}_{3}(17 \%$ versus $30 \%$ on the glutamine supplemented medium), and the number of developed structures from the responding anthers was lower. Embryoids were seldom observed, and the sur- face of the majority of formed structures were more amorphous, comparable to that observed in callus cultures. Some of these cultures turned brown in time, and necrotic arrest was observed, probably as a response to the high level of ammonium nitrate.

The same effect of the nitrogen source was observed on anthers cultivated on liquid medium containing-Ficoll.

The data in Table III show that the lower level of $\mathrm{NH}_{4} \mathrm{NO}_{3}$ in combination with glutamine gave a higher frequency of responding anthers, and that the responding anthers gave rise to more structures. Also the ratio between green plants and albino plants $(\mathrm{G} / \mathrm{A})$ increased in response to the reduction in the concentration of ammonium nitrate and the addition of glutamine. On the glutamine supplemented medium the G/A ratio was 1.5 compared to 0.8 for anthers cultivated on medium containing $20 \mathrm{mM}-\mathrm{NH}_{4} \mathrm{NO}_{3}$ and no glutamine. The difference in the number of responding anthers as well as in the green and albino plants per responding anther on the two media was significant at the $5 \%$ level (students T-test).

Regeneration of plants from calli is known to 
give a high level of albino plants (4), which agrees with the observed concurrent reduction in the number of calli and albino plants on the medium with low level of ammonium nitrate.

The results from this study show that the potential embryoid formation of microspores is depressed by high levels of ammonium nitrate, whereas low levels in combination with glutamine are able to promote the development of embryoids from microspores of cultivated anthers.

\subsubsection{Experiment 2. Comparison of different glutamine concentrations}

This experiment was performed to determine the optimal glutamine concentration for induction of embryoid in cultivated anthers. The procedure was similar to that used in experiment 1.

The data are based on 10 spikes, with 60 anthers per spikes. The three anthers from each floret were distributed onto three media containing 3.4, 5.1 and 6.8 mM-glutamine, respectively (Table II). The inoculum was 2 anthers per milliliter. All the cultures in this experiment showed an embryogenic development similar to that seen in cultures containing $5.1 \mathrm{~mm}$-glutamine as described in section 3.1.1.

The results in Table II indicate that a glutamine concentration of $5.1 \mathrm{~mm}$ gave an optimal response both with regard to the number of responding anthers and to the yield of green plants per responding anther, the latter amounting to 3.9. Green plants per responding anther on the media with 3.4 or $6.8 \mathrm{~mm}$-glutamine were $87 \%$ and $85 \%$, respectively, of maximum yield, in relation to $5.1 \mathrm{~mm}$ per liter, the higher glutamine exhibiting a slightly higher ratio between green and albino plants.

It thus appears that changes in the concentration of glutamine between 3.4 and $6.8 \mathrm{~mm}$ only lead to marginal changes in the response, the optimal concentration being $5.1 \mathrm{~mm}$.

\subsection{Ficoll as a buoyancy increasing agent in liquid media}

The use of Ficoll 400 as a buoyancy increasing agent in liquid media for barley anther culture has previously been described by KAO and HORN (15) who reported an increase in the number of responding anthers (i.e., anthers bearing calli) as well as the number of calli per anther when anthers were plated on liquid medium containing 20\% Ficoll 400 . The increase was accompanied by a decrease of the $\mathrm{pH}$ of the liquid medium during the culture period. It was further shown by DATTA (4) that pollen embryogenesis was observed in cultures of cold pretreated barley spikes on liquid medium containing 100 g Ficoll 400 per liter. These experiments thus indicated that liquid media containing Ficoll 400 could be used as an alternative to media solidified by agarose.

The induction medium used in the present experiments was a modified MS medium containing $200 \mathrm{~g}$ of Ficoll 400 instead of agarose (Table II). The culture procedure was as described in section 2.2.2 except that the watercontaining Petri dish present during the incubation was omitted. When anthers were cultivated on liquid media containing Ficoll a twofold increase of the number of responding anthers was observed (Table III). The increase was accompanied by a more synchronous development of the embryoids. The $\mathrm{pH}$ of the liquid medium decreased from 5.6 at the start of cultivation to $\mathrm{pH} 5.0$ after 3 weeks. In the following 2 weeks, the pH increased, reaching approximately 5.8 after 35 days of culture.

The incubation temperature strongly influences the yield in liquid media, with respect to the number of responding anthers, the yield per responding anther and the ratio between green and albino plants. In an experiment with four spikes, the anthers from both half spikes were plated on liquid medium I. Anthers from one side of the spike were incubated at $25^{\circ} \mathrm{C}$ constant, and anthers from the other side at $30^{\circ} \mathrm{C}$ for 24 hour, and thereafter maintained at $25^{\circ} \mathrm{C}$. The initial heatshock resulted in a $16 \%$ reduction of the number of responding anthers, a 70\% reduction in the number of green plants per responding anther, and an increase in the number of albino plants of $37 \%$. Compared to the control the ratio between green plants and albino plants dropped from 1.4 to 0.5 . This shows that the incubation temperature is a crucial element in anther culture on liquid medium. 

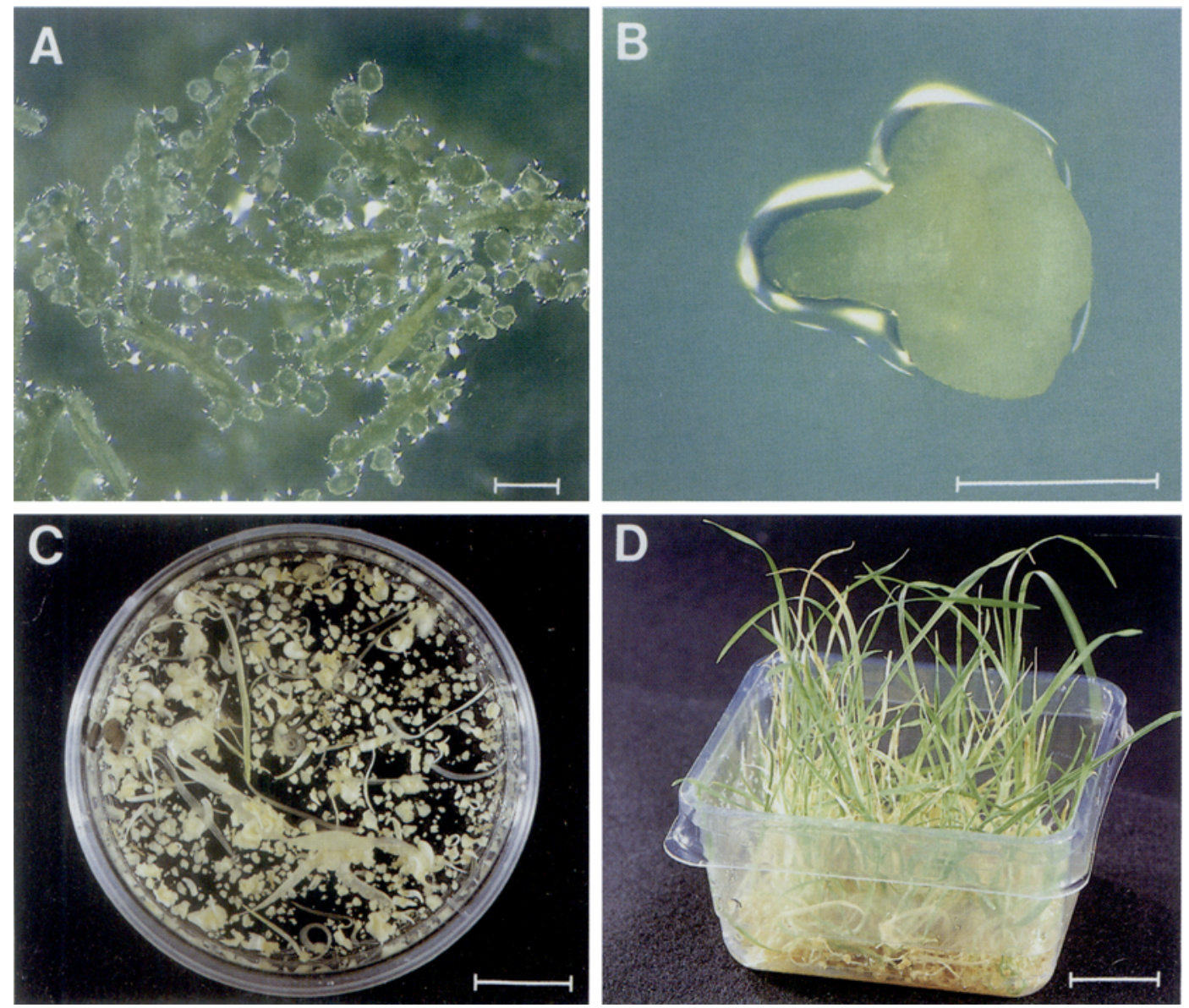

Figure 2A. Anthers floating on a Ficoll medium showing the liberated proembryoids after 10-14 days of culture. $(\mathrm{Bar}=1 \mathrm{~mm})$.

Figure 2B. Well-formed embryoid from liquid anther culture, with distinguishable coleoptile and coleorhiza oriented with the scutellum towards the solid surface of the medium II. (Bar $=1 \mathrm{~mm}$ )

Figure 2C. Proembryoids on liquid induction medium after 3-4 weeks. $(B a r=10 \mathrm{~mm})$.

Figure 2D. Dancon plant container (without lid) 3 weeks after the transfer from the primary liquid cultures. (Bar $=50 \mathrm{~mm}$ )

The following experiments were performed using $3.4 \mathrm{~mm}$ or $5.1 \mathrm{~mm}$ of glutamine to determine the optimum glutamine level in the Ficoll medium (experiment 3) and to compare the effects of replacing glutamine by asparagine as a nitrogen source at a concentration of $5.1 \mathrm{~mm}$ (experiment 4).

\subsubsection{Experiment 3. Comparison between 3.4 $\mathrm{mM}$ - and $5.1 \mathrm{~mm}$-glutamine in liquid medium \\ In experiment 2 maximum response was} obtained when the concentration of the glutamine in the agarose solidified medium was of $5.1 \mathrm{mM}$. Theoretically, the amount of glutamine required for maximum response in a liquid medium is expected to be the same or lower due 
to a higher diffusion rate in a liquid medium. In this experiment anthers from either side of the spike were plated on liquid media I with $3.4 \mathrm{~mm}$ and $5.1 \mathrm{~mm}$-glutamine, respectively.

The data given in Table III are based on 14 spikes, 60 anthers per spike, plated at a density of 3 anthers per mililiter of medium. No attempt was made to orient the anthers on the surface of the buoyant medium. The cultures were incubated as described for cultures on solid media in section 2.2.2. Immediately after plating, most anthers floated on the medium with both loculi in contact with the surface, while only few anthers were in contact with the medium with a single loculus. After the first week all the anthers had both loculi in contact with the medium.

After developing inside the anther loculus for one week, the growing proembryoids increase in volume causing the anther wall to burst (see Figures $1 \mathrm{~B}$ and $2 \mathrm{~A}$ ). The liberated proembryoids are expelled from the anther and become distributed uniformly over the surface of the medium. (Figure 2C). Hence the manual manipulation of calli and embryoids required when cultivation is performed on solid media (see section 2.2.2) is not necessary. Obviously, this greatly facilitates the manual work, and simultaneously reduces the risk of mechanical damage to the minute calli and embryoids as well as the risk of fungal infection. After liberation from the anther, the embryoids float to the surface of the Ficoll medium and start to germinate forming small plantlets (Figure 2C).

In media containing glutamine, or asparagine (see experiment 4), some of the microspores which undergo direct embryogenesis, germinate without complete development of the scutellum (premature germination) (see Figure 2C). After 3-4 weeks the embryoids and plantlets larger than 2-3 $\mathrm{mm}$ are harvested and transferred to the agarose containing medium II, ensuring that the scutellum remains in contact with the medium (ses Figure 2B). At the same time the medium in the primary culture container was replaced by fresh medium I. After 7-8 weeks the rest of the cultures and the liquid medium were emptied into Dancon plant containers (Teknunc, Roskilde, Denmark), holding $50 \mathrm{ml}$ solid medium II, (see Figure 2D) and the residual liquid medium was removed with a pipette. The cultures in Dancon plant containers were incubated as described for cultures on medium II, in section 2.2.2.

The results given in Table III indicate that cultures on $5.1 \mathrm{~mm}$-glutamine developed best in comparison to the cultures on $3.4 \mathrm{mM}$, the yield of green plants per responding anther exceeding the frequency obtained on the lower glutamine concentration by $15 \%$, quite similar to the difference in response obtained in experiment 2 .

Other experiments have shown that the emptying of cultures into the Dancon plant containers rather than carefully transferring and orienting the embryoids and plantlets, reduces the yield of green plants and albino plant by $5 \%$ and $25 \%$, respectively. The more pronounced yield reduction of the albino plants is due to their frequent development from a layer of calli covering a considerable area in the container. The more rapidly growing green plants then often outgrow the albino plants.

\subsubsection{Experiment 4. Comparison between glutamine and asparagine}

The aim of this experiment was to investigate if asparagine could substitute for glutamine as a nitrogen source. The two amino acid, both have an amide side chain, and both function as non toxic nitrogen carriers in plants (2).

The experiment was performed as described for experiment 3. The comparison was based on equal numbers of anthers from each side of the spike. The experiment included 15 spikes, 60 anthers per spike, the inoculum density beeing 3 anthers per milliliter of liquid medium.

The initial observations show that the cultures on $5.1 \mathrm{mm-glutamine} \mathrm{developed} \mathrm{faster} \mathrm{than}$ cultures on $5.1 \mathrm{~mm}$-asparagine, whereas the number of calli and embryoids per anther was about the same.

After 3 weeks of culture the $\mathrm{pH}$ value was determined to be 5.2 for the glutamine supplemented medium and 5.0 for the medium containing asparagine. During the following 16 days the $\mathrm{pH}$ was measured 3 times per dish revealing a linear increase of the $\mathrm{pH}$ reaching 5.9 for the glutamine medium and 5.7 for the asparagine medium. The $\mathrm{pH}$ determinations were based on 112 measurements, on 14 pairs of cultures. 
The quantitative data in Table III show that $5.1 \mathrm{~mm}$-glutamine is slightly superior to 5.1 $\mathrm{mm}$-asparagine, perhaps due to the higher $\mathrm{pH}$ value during culture of the former medium. As can be seen in Table III there was a higher number af responding anthers on medium with $5.1 \mathrm{~mm}$-glutamine. The yield of green plants per responding anther was 3.9 versus 3.6 for the medium containing asparagine, and the ratio between green and albino plants being 1.7 and 1.4, respectively. The difference in the yield of green plants per responding anther, on medium with $5.1 \mathrm{~mm}$-glutamine, in experiment 3 (5.7) and in this experiment (3.9) (a reduction in yield on $32 \%$ ), is most likely due to the removal of aliquot of medium for $\mathrm{pH}$ determination in the latter experiment, which reduced the volume of liquid medium by about $16 \%$.

\subsection{Chromosome number of the regenerated plants}

Cytological examination of metaphase chromosomes from roottips of 50 regenerated green plants showed that $94 \%$ of the plants were diploid, in agreement with earlier observations by HUANG and SUNDERLAND (11) (200 plants 97\% seed set) and LYNE et al. (17) (20 plants $90 \%$ diploids). Thus also under the present condition diploidization occurs readily during embryogenesis or regeneration of plants.

\section{CONCLUSION}

Development of microspores from cultivated anthers into embryogenic tissue was first reported for spring barley by LYNE et al. (17). Subsequently, the response in the form of embryoid formation was significantly improved by carefully controlling the growth condition of the donorplants, and orientation of the anther (12). Under optimal conditions for the winter barley variety Igri up to 0.02 green plants per plated anther has been reported (8). In this investigation a frequency of 4.6 green plants per plated anther has been achieved.

The present work has shown that especially two parameters of the culture procedure are of critical importance for a further improvement of the yield of green plants, namely the nitrogen source and the gelling agent used to solidify or thicken the medium.

The use of $20 \mathrm{~mm}-\mathrm{NH}_{4} \mathrm{NO}_{3}$ in the medium used for induction of microspore development was observed to severely suppress the formation of embryoids and instead induce formation of unstructured calli in anthers cultivated on solid medium. If regeneration occurs mainly from calli and only to a minor extent from embryoids, the overall response is low and most of the regenerated plants are white. Brown miscolouring of callus tissue is frequently observed, indicating suboptimal culture conditions. Reduction of the concentration of ammonium nitrate to $2 \mathrm{mM}-\mathrm{NH}_{4} \mathrm{NO}_{3}$ and addition of $5.1 \mathrm{mM}$-glutamine markedly altered the developmental pattern of the microspores of cultivated anthers. The proportion of embryoids from which green plants are readily regenerated, increased, and the number of green plants exceeded the number of albino plants.

The results show that glutamine stimulates direct embryogenesis from microspores in agreement with previus observations on tissue culture of Nicotiana (24), Datura (25) and Triticum (10).

The optimal concentration of glutamine was found to be $5.1 \mathrm{~mm}$ or $750 \mathrm{mg}$ per liter solid medium. Concentrations on 500 and $1000 \mathrm{mg}$ per liter yielded slightly fewer green plants per responding anther.

Liquid media have proved to be efficient for androgenesis. Substitution of solid media containing agarose by liquid medium in which the density has been increased by addition of $20 \%$ Ficoll 400 in combination with media containing glutamine or asparagine has, to a large extent, eliminated the callus phase and promoted the formation of embryoids directly from the microspores. As decribed in section 3.2.1 the use of liquid media offers the additional advantage of reducing the time consuming transfer and orientation of the embryoids and plantlets.

The culture medium can be changed during the induction period by removing the old medium with a pipette and adding the new culture medium thus permitting the analysis of for example the effect of growth hormones such as abscisic acid or gibberellic acid in controlling culture development. 


\section{ACKNOWLEDGEMENTS}

I would like to thank professor DITER vON WetTSTEIN and Dr. JørgeN LARSEN for their continued encouragement during the course of this work and for generously providing facilities at the Department of Physiology and at the Carlsberg Research Farm. I am indebted to Dr. CLIFF HUNTER for expert advise and valuable discussions, Dr. Søren W. RASMUSSEN, for critically reading the manuscript, BøRGE PETERSEN. Søren KnUdSEn and Jean SAGE for technical assistance, and to NINA RASMUSSEN and ANNSofi SteinhIOLTZ for art work. The financial support of the Biomolecular Action Programme of the European Community (Contract BAP0091-DK) is gratefully acknowledged.

\section{REFERENCES}

1. ARAKI.C.: Structure of the agarose constituent of agar-agar. Bull Chem. Soc. Japan 29, 543-544 (1956)

2. BeEvers. L.: Nitrogen metabolism in plants. Edvard Arnold (publisher) Ltd. London (1976)

3. Clapham. D.: Haploid Hordeum plants from anthers in vitro. Z. Pflanzenzüchtg. 69, 142-155 (1973)

4. DatTA. S. K.: Plant regeneration by pollen embryogenesis from cultured whole spikes of barley (Hordeum vulgare). Theor. Appl. Genet 74, 121124 (1987)

5. Dunwfel.., J. M.: Anther culture in Nicotiana tabacum: The role of the culture vessel atmosphere in pollen embryo induction and growth. J. Exp. Bot. 30, 419-428 (1979)

6. Dunwell. J. M.: Stimulation of pollen embryo induction in tobacco by pretreatment of excised anthers in a water-saturated atmosphere. PI. Sci. Lett. 21, 9-13 (1981)

7. Forolghi-Wehr. B.. G. Mix. H. Gaul. H. M. WILSON: Plant production from cultured anthers of Hordeum vulgare L. Z. Pflanzenzüchtg. 77. 198-204 (1976)

8. Foroughi-WeHR. B. \& W. FrIedt: Rapid production of recombinant barley yellow mosaic virus resistant Hordeum vulgare lines by anther culture. Theor. Appl. Genet. 67, 377-382 (1984)

9. HaGberg. A. \& G. HaGberG: High frequency of spontaneus haploids in the progeny of an induced mutation in barley. Hereditas 93, 341-343 (1980)

10. HENRY. Y. \& J. DE BLYSER: Float cultures of wheat anthers. Theor. Appl. Genet. 60, 77-79 (1981)

11. HuANG. B. \& N. SUNDERLAND: Temperature-stress pretreatment in barley anther culture. Ann. Bot. 49, 77-88 (1982)

12. HUNTER. C. P.: The effect of anther orientation on the production of microspore-derived embryoids and plants of Hordeum vulgare cv. Sabarlis. Plant Cell Rep. 4, 267-268 (1985)

13. JeNSEN. C. J.: Barley monoploids and doubled monoploids: Techniges and experiences. In: Barley Genetics III (Ed. H. Gaul), pp. 316-345. Verlag Karl Thiemig, Munchen (1975)

14. KaSha. K. J. \& K. N. KaO: High frequency haploid production in barley (Hordeum vulgare L. ). Nature 225, 874-876 (1970)

15. KAO.K. N. \& D. C. HORN: A method for induction of pollen plants in barley. In: Proc. 5th Intl. Cong. Plant Tissue and Cell Culture. Plant Tissue Culture 1982. Ed. Akio Fujiwara (1982)

16. KAO. K. N. \& D. C. HORN: Induction of pollenplant formation in barley anther culture. International Symposium on Genetic Manipulation in Crops. October 22-26, Beijing, China (1984)

17. LYNE. R. L.. R. I. BENNETT \& C. P. HUNTER: Embryoid and plant production from cultured barley anthers. In: Plant Tissue Culture and its Agricultural Application. University of Nottingham. pp. 405-411. Eds. L. A. Withers and P. G. Alderson. Butterworth, pub., Guildford (1984)

18. Murashige. T. \& F. Skoog: A revised medium for rapid growth and bioassays with tobacco tissue cultures. Physiol. Plant. 15, 473-497 (1962)

19. NitsCh. C:: La culture de pollen isolé sur milieu synthétique. C. R. Acad. Sci., Paris (Ser. D), 278. 1031-1031 (1974)

20. Nitzsche. W. \& G. WenZel: Haploids in plant breeding. Supplement 8 to Journal of Plant Breeding. Ed. W. Horn and G. Röbbelen. Verlag Paul Parey, Berlin (1977)

21. Pickering. R. A.: Use of the doubled haploid technique in barley breeding at the Welsh plant breeding station. Ann. Rep. from the Welsh Plant Breeding Station (1979)

22. Shillito. R. D.. J. Paszkowski \& I. Potrykls: Agarose plating and a bead type culture technique enable and stimulate development of protoplastderived colonies in a number of plant species. Plant Cell Rep. 2. 244-247 (1983)

23. SOPORY.S. K.\& S.C.MAHESHWARI: Development of pollen embryoids in anther cultures of Datura innoxa. 1. General observations and effects of physical factors. J. exp. Bot. 27, 49-57 (1976)

24. WeR.NICKE. W.\& H W. KOHLENBACH: Experiments on the culture of isolated microspores in Nicotiana and Hyoscyamus. Z. Pflanzenphysiol. 81, 330340. (1977)

25. Wetherell. D. F. \& D. K. Dolgall: Sources of 
F .L. OLSEN: Microspore embryogenesis in anthers of Hordeum

nitrogen supporting growth and embryogenesis in cultured wild carrot tissue. Physiol. Plant. 37, 97-103 (1976)

26. XU, Z. H. \& N. SUNDERLAND: Glutamine, inositol and conditioning factor in the production of barley pollen callus in vitro. Plant Sci. Lett. 23, 161-168 (1981)

27. YANG, H. Y. \& C. ZHOU: In vitro induction of haploid plants from unpollinated ovaries and ovules. Theor. Appl. Genet. 63, 97-104 (1982)

Accepted by S. O. ANDERSEN 